\title{
Commentary: Is surgical field insufflation with carbon dioxide an antidote for airhead(s)?
}

\author{
R. Scott Mitchell, MD
}

\author{
From the Department of Surgery, V.A. Hospital Palo Alto, Palo Alto, Calif; and Department of Cardiothoracic \\ Surgery, Stanford University School of Medicine, Stanford, Calif. \\ Disclosures: Author has nothing to disclose with regard to commercial support. \\ Received for publication April 29, 2019; accepted for publication April 29, 2019; available ahead of print June 21, \\ 2019. \\ Address for reprints: R. Scott Mitchell, MD, 3801 Miranda Ave, Palo Alto, CA 94304 (E-mail: rsmitch@ stanford. \\ edu). \\ J Thorac Cardiovasc Surg 2020;159:970 \\ 0022-5223/\$0.00 \\ Published by Elsevier Inc. on behalf of The American Association for Thoracic Surgery \\ https://doi.org/10.1016/j.jtcvs.2019.04.099
}

Carbon dioxide $\left(\mathrm{CO}_{2}\right)$ field insufflation is an attractive adjunct during open heart surgery because of the markedly increased solubility of $\mathrm{CO}_{2}$ in blood versus air. However, to date this strategy remains unproven. I can recall from the distant past, before the use of $\mathrm{CO}_{2}$ insufflation, and before the availability of transesophageal echocardiography (TEE), many patients awakening from cardiac surgery experienced confusion and severe agitation but without focal neurologic deficits. These were considered to secondary to air emboli, and such patients were deemed "airheads."

Fortunately, these symptoms cleared within 3 to 4 days without obvious long-term sequalae. With the advent of TEE, which allowed visualization of gaseous bubbles within cardiac chambers, deairing maneuvers could be more directed, and more complete, and at about the same time, many surgeons added $\mathrm{CO}_{2}$ insufflation to their routines. With this combined regimen, to my admittedly imperfect recollection, this postoperative agitated state virtually disappeared. However, other than anecdotal reports, is there any valid evidence for improved neuroprotection?

Chaudhuri and colleagues ${ }^{1}$ demonstrated significantly more rapid and complete clearing of intracardiac air after left-sided valve procedures in a randomized trial with and without $\mathrm{CO}_{2}$, as judged by blinded anesthesiologist assessment from the TEE. Herrmann and colleagues ${ }^{2}$ demonstrated significantly lower levels of $\mathrm{S} 100 \beta$ at 2 and 48 hours after a pump run, suggesting less axonal injury, and Martens and colleagues ${ }^{3}$ similarly demonstrated less prolonged p300 peak latencies in the $\mathrm{CO}_{2}$ group versus controls. However, there have been no definitive trials, to my knowledge, demonstrating fewer neurologic deficits or less neurocognitive decline.

So what are we to do? Based on the increased solubility of $\mathrm{CO}_{2}$ in blood, the trivial added expense, and more efficient

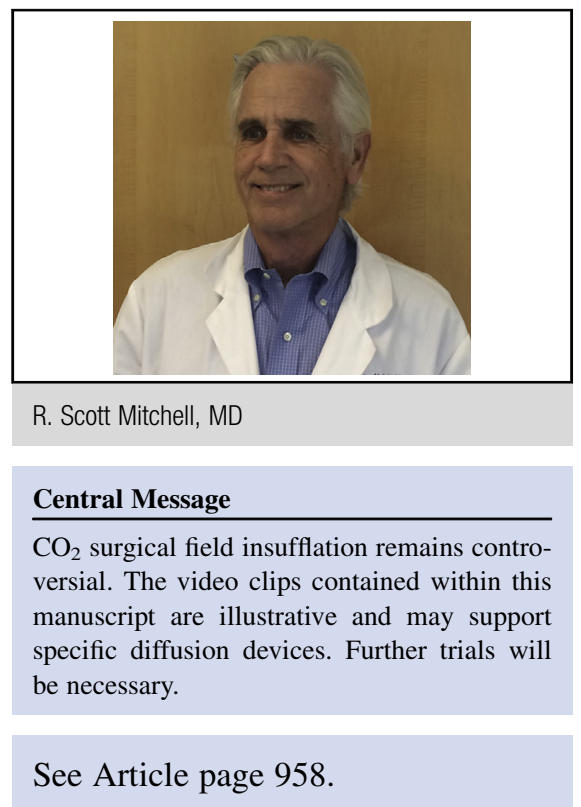

and shortened deairing times, $\mathrm{CO}_{2}$ could offer additional protection with little downside. The excellent videos and discussion in the manuscript by Vandenberghe and colleagues ${ }^{4}$ highlight marked differences in dispersion patterns with different devices and flow rates, which may affect efficacy with this technique. Going forward, randomized controlled trials using diffusors that can effectively maintain a homogenous $\mathrm{CO}_{2}$ cloud over the operative field may be necessary to demonstrate a clinical benefit. The prevention of even one "airhead" would seem worth the effort.

\section{References}

1. Chaudhuri K, Storey E, Lee GA, Bailey M, Chan J, Rosenfeldt FL, et al. Carbon dioxide insufflation in open chamber cardiac surgery: a double-blind, randomized clinical trial of neurocognitive effects. J Thorac Cardiovasc Surg. 2012;144: 646-53.

2. Herrmann M, Ebert AD, Galazky I, Wunderlich MT, Kunz WS, Huth C. Neurobehavioral outcome prediction after cardiac surgery: role of neurobiochemical markers of damage to neuronal and glial brain tissue. Stroke. 2000;31:645-50.

3. Martens S, Neumann K, Sodemann C, Deschka H, Wimmer-Greinecker G, Moritz A. Cardon dioxide field flooding reduces neurologic impairment after open-heart surgery. Ann Thorac Surg. 2008;85:543-7.

4. Vandenberghe S, Iseli D, Demertzis S. Direct visualization of carbon dioxide field flooding: optical and concentration level comparison of diffusor effectiveness. $J$ Thorac Cardiovasc Surg. 2020;159:958-68. 